\title{
CONSTELAÇÕES FAMILIARES: UMA ANÁLISE DOS PONTOS NEGATIVOS E POSITIVOS ACERCA DA SUA APLICAÇÃO NO DIREITO DE FAMÍLIA
}

\author{
FAMILY CONSTELLATIONS: AN ANALYSIS \\ OF NEGATIVE AND POSITIVE POINTS ABOUT \\ THEIR APPLICATION IN FAMILY LAW
}

\section{Bruna Nogueira Trizotti ${ }^{1}$}

Resumo: $O$ presente trabalho quanto aos acordos judiciais. buscou compreender mais pro- Embora se trate de um método fundamente o instituto da cons- não convencional e necessite de telação familiar, verificando seus aperfeiçoamento, tal instituto está aspectos positivos e negativos. auxiliando não somente as partes, Trata-se de um tema relativamen- mas o Poder Judiciário em sua te novo e que tem contribuído totalidade, diminuindo os índices para o direito de família, em especial para a resolução de conflitos, ao lado de métodos, como a conciliação e a mediação. Por isso, é essencial analisar como essa ferramenta que vem ganhando espaço no mundo jurídico está se desenvolvendo no dia a dia. A partir do presente estudo, foi possível averiguar que sua aplicação tem surtido efeitos satisfatórios de reincidência processual.

Palavras-chave: Constelação. Família. Direito sistêmico.

Abstract: The present work sought to understand more deeply the institute of the family constellation, verifying its positive and negative aspects. This is a relatively new topic and one that has contributed to family law,

1 Pós-graduanda; Escola Superior da Magistratura de Santa Catarina (ESMESC); Residente judicial. E-mail: brunanogueiratrizotti@, gmail.com 
in particular conflict resolution, ing the judicial agreements. Alalongside methods such as con- though it is an unconventional ciliation and mediation. That is method and needs improvement, why it is essential to analyze how this tool that has been gaining space in the legal world is developing on a daily basis. From the present study, it was possible to ascertain that its application has had satisfactory effects regardthis institute is helping not only the parties, but the Judiciary as a whole, reducing the rates of procedural recidivism.

Keywords: Constellation. Family. Systemic law.

\section{INTRODUÇÃ̃O}

No decorrer deste artigo, pretende-se analisar as constelações familiares e sua incidência nas ações de família. Isso porque é preciso trazer para a realidade um meio que resolva o conflito interno das partes e o processo judicial concomitantemente, bem como seja capaz de restituir os laços familiares no intuito de conter a reincidência processual.

Portanto, será essencial discorrer sobre a experiência do Juiz Samir Storch, que tem alcançado índices extraordinários de conciliação com a utilização do método psicoterapeuta da constelação familiar criado pelo alemão Bert Hellinger.

Além do que é preciso observar que as desavenças familiares tratam de um problema experimentado por inúmeras pessoas. É por isso que surge a necessidade de auxiliar as famílias a lidarem com seus sentimentos uns pelos outros.

Diante disso, nota-se a importância em abordar esse tema, afinal, ao verificar os resultados positivos obtidos com o uso da constelação familiar, é possível ampliar as ferramentas para tratar dos conflitos familiares de forma mais humanizada. 


\section{O CONTEXTO HISTÓRICO ACERCA DA CONSTELAÇÃO FAMILIAR}

Inicialmente, tem-se que a constelação familiar diz respeito a um método criado por Bert Hellinger, que era um psicoterapeuta alemão. A partir da constelação, são feitas esculturas vivas que reconstroem a árvore genealógica, o que permite localizar e remover bloqueios do fluxo amoroso e afetivo de qualquer geração ou membro da família (SANTOS, 2020).

A constelação familiar sistêmica se estabeleceu a partir da vivência de Hellinger, que desenvolveu sua própria terapia sistêmica e familiar usando diferentes técnicas. Um método revolucionário das constelações familiares. Considera-se o método da constelação familiar sistêmica uma abordagem da psicoterapia sistêmica fenomenológica e que pode ser aplicada em várias áreas da vida (CARVALHO, 2012).

É certo que a constelação de sistemas sociais se estabeleceu em vários países no decurso dos anos 90 como um método de aconselhamento e terapia em muitas áreas, tais como, escolas, presídios e na consultoria política e organizacional. Além disso, é importante mencionar que esse método se encontra em permanente expansão (HAUSNER, 2010).

Para Schneider (2007, p. 95), as constelações parecem produzir bons efeitos, sobretudo em relação aos seguintes objetivos:

Resolver conflitos conjugais e familiares, melhorar comportamentos inadequados de crianças, solucionar problemas na escola, no trabalho e em decisões, resolver conflitos de filhos com os seus pais, encontrar paz familiar e paz na alma, diminuir riscos de suicídio e de acidentes e, de um modo geral, fortalecer a vida em sua energia. Também têm sido relatadas melhoras de sintomas, por exemplo, em casos de medo, de compor- 
tamentos compulsivos como bulimia e anorexia e em enfermidades, como a dermatite alérgica.

A constelação familiar pode ser caracterizada como um método profissionalmente dirigido, visando à superação de crises pessoais e familiares na vida. Nessa condição, ela pode ser apresentada e aprendida. Tanto a apresentação quanto o aprendizado exigem uma grande abertura em relação ao seu procedimento metódico (SANTOS, 2020).

Isso porque as pessoas possuem a tendência de esperar dos métodos para a resolução de problemas algo semelhante ao que oferecem os métodos técnicos das ciências naturais, a saber, confiança e previsibilidade. Ou seja, é esperado que o método seja comprovado, dê segurança e, quando possível, proporcione resultados desejáveis e previsíveis. No entanto, tendo em vista que durante as seções de constelação várias coisas podem acontecer, os resultados não são previsíveis, mesmo porque existem sentimentos em jogo (SCHNEIDER, 2007).

De acordo com Santos (2020), trata-se de um ensinamento que olha para o presente, o passado e o futuro. A prática de constelar desenvolve nas pessoas o senso de equilíbrio e de paz e o entendimento de sua importância no eixo familiar. Com o auxílio desse método, é possível identificar os males que foram causados uns aos outros, assim como reconstruir o elo familiar. Em outras palavras, a constelação pode servir como um instrumento no direito de família, especialmente nas situações que envolvam guarda, alimentos e divórcio.

Nos estudos da terapia familiar sistêmica, é possível avaliar a construção da árvore genealógica da família e ver se existe, por exemplo, alguém que "esteja emaranhado" nos destinos de membros das gerações passadas. Isso pode ser elucidado a partir do trabalho com sessões de constelações familiares. Esse método de terapia visa avaliar os conflitos existentes no eixo 
familiar que podem ser gerados pela ausência de um membro. Para ilustrar, será dado o exemplo de um casal que se separa. Esse distanciamento deixará na família um espaço vazio que somente será preenchido mediante a resolução do problema que gerou a separação (SANTOS, 2020).

A consequência de não solucionar o caso, considerando que esse casal hipotético tivesse um filho, possivelmente seria de uma criança que cresce sem a presença masculina, ou seja, sem ter o referencial de um pai. Provavelmente, essa falta fará com que a mãe seja compelida a desenvolver o papel de pai e mãe e, mesmo assim, essa ausência não será suprida, sempre existirá uma lacuna (ARAÚJO, 2015).

Desse modo, o entendimento desenvolvido pela constelação é de que não se pode inverter as ordens no seio familiar, pois, toda vez que isso acontece, essa família passará a viver um emaranhamento. Hellinger $(2017$, p. 13) leciona o conceito dessa palavra para a constelação familiar: "emaranhamento significa que alguém na família retoma a reviver inconscientemente o destino de um familiar que viveu antes dele". Como exemplo, é possível pensar em uma criança que foi entregue para adoção. $\mathrm{O}$ autor explica que, em uma família, quando uma criança é entregue para adoção em uma determinada geração, possivelmente um membro dessa família se comportará como se ele tivesse sido entregue também para doação em uma geração futura. Nesse caso, se ele não conhecer esse emaranhamento, não conseguirá se livrar dele. Passará a viver com o sentimento de rejeição, como se ele não fosse amado pela família a que pertence.

Ele sugere uma solução para esses casos: “[...] a pessoa que foi entregue para adoção entra novamente em jogo. É colocada na constelação familiar. De repente, a pessoa que foi excluída da família passa a ser uma proteção para aquela que estava identificada com ela." (HELLINGER, 2017, p. 13). Essa pessoa, quando volta a fazer parte do sistema familiar, retorna ao 
seu lugar de origem, preenchendo um "espaço que antes estava vazio". Esse ente familiar também recebe honra e o afeto que lhe foi negado por ter sido retirado do sistema familiar.

Isso implica em dizer que a injustiça cometida por gerações anteriores será representada e sofrida por alguém nessa família futuramente. Se desse relacionamento, por exemplo, houver a geração de um filho, essa criança será possivelmente rejeitada e sofrerá as consequências de um erro cometido anterior a ela. Portanto, deve-se restaurar os sentimentos do grupo para que retome o equilíbrio entre as partes; os excluídos precisam ser reabilitados. E é nesse sentido que a constelação familiar se apresenta (SANTOS, 2020).

Assim, nota-se que essa terapia visa reestabelecer um sistema e buscar uma forma de recompor a família que está desestruturada em detrimento de alguma desordem. Compreende-se ainda que:

Os sistemas familiares têm uma força tão grande, vínculos tão profundos e algo tão comovente para todos os membros - independentemente de como se comportem em relação a eles - , que eu confio totalmente neles. A família dá a vida ao indivíduo. Graças à família, ele nasce no seio de um determinado povo, em uma determinada região e é vinculado a determinados destinos e tem que arcar com eles (HELLINGER, 2017, p. 81).

Hellinger (2017) revela também que esse método de constelação advém de três ordens que ele denomina de ordens do amor. São elas: o direito de pertencer, a hierarquia e o equilíbrio. Essas ordens devem ser respeitadas para que não surjam emaranhamentos. Elas exercem papel fundamental para a preservação do sistema familiar. Por isso, é possível afirmar que essas leis servem de pilares na constelação familiar.

A primeira lei é o direito de pertencer. Todo indivíduo tem direito de pertencer a uma família, essa é uma necessidade hu- 
mana. Toda vez que um membro abandona seu lugar de origem ou seu lar atual é gerada uma lacuna, porque cada pessoa tem um lugar a ser ocupado no sistema. Pertencer quer dizer também que o familiar não pode ser expulso ainda que exista motivos de dificuldade de convivência ou suas características pessoais (HELLINGER, 2017).

Em outras palavras: "Pertencer é fazer parte de um grupo familiar e ser reconhecido por ele." (ISLIKER, 2016, p.18).

Segundo Santos (2020), a lei do pertencimento é irrevogável. É um direito que não pode ser negado a nenhum ente familiar, ainda que essas pessoas tenham cometido atitudes condenáveis, pecaminosa ou reprováveis, como: usar entorpecentes, alcoolismo, abortos ou que sejam mães solteiras, não podem ser excluídas do sistema familiar, pois uma vez que pertenceu àquela família, ainda que morra, continuará a pertencer.

É certo que a exclusão nunca foi nem será solução para corrigir ninguém. Esse tipo de atitude causa desordem na família e em qualquer outro tipo de sociedade. Ter consciência disso trará mudanças de atitudes e quebra de paradigmas (SANTOS, 2020).

A segunda ordem do amor é a hierarquia. De acordo com Isliker (2016, p. 18), a hierarquia pode ser explicada do seguinte modo: "[...] os que vieram antes têm precedência aos que vieram depois. Isso significa que pais têm precedência aos filhos e os relacionamentos anteriores desses pais também têm um lugar de respeito na história de cada cônjuge".

Para Hellinger (2017), a segunda lei faz referência a quem chegou primeiro. Essa lei diz que quem chegou primeiro merece ser respeitado, pois a família surgiu com os que chegaram primeiro, o respeito à hierarquia transcende o entendimento humano.

Uma vez que essa hierarquia não é respeitada ocorre o emaranhamento, que pode ser descrito da seguinte forma: fi- 
lhos quando assumem responsabilidade no lugar dos pais, assim como também o inverso, pais que não assumem seu papel. Essa inversão de papéis tende a causar inúmeros desajustes. Por isso, é essencial que cada integrante da família respeite seu papel (SANTOS, 2020).

A consequência desse emaranhado é uma geração de filhos que não obedecem aos pais, que não aceitam opinião dos seus genitores; e o prejuízo é a desarmonia da casa e sentimentos opostos em um mesmo lar. Por outro lado, quando são os pais que não assumem seu lugar na família, causam prejuízo ao filho, pois o desenvolvimento dessa criança será impedido, tornando-o dependente, fraco e com o desenvolvimento social comprometido. Dessa forma, fica evidente o quanto é importante respeitar os que vieram primeiro.

A terceira e última ordem do amor é o equilíbrio do dar e do receber. Em suma: "[...] deve se dar apenas o que se tem e somente esperar e tomar o que se necessita." (ISLIKER 2016, p. 19). O desequilíbrio é uma ferramenta destrutiva em qualquer relação, seja ela pessoal ou interpessoal. Com pais e filhos, não é diferente. Pode ser constatado quando o filho exige do pai além de suas condições, como também quando o pai não oferece estrutura suficiente para que o filho se desenvolva com qualidade. $\mathrm{O}$ abandono, por exemplo, também gera o desequilíbrio.

Ademais, todo ser é dotado da capacidade de troca, oferecendo aos outros seus dons, capacidades e habilidades, recebendo daqueles o que for importante para satisfazer suas necessidades de sobrevivência, crescimento e desenvolvimento (GONÇALVES, 2017).

\section{Segundo Carvalho (2012, p. 43):}

Quando estas ordens são aplicadas, cessa a responsabilidade por injustiças cometidas no grupo familiar. As culpas e as consequências retornam às pessoas a que pertencem, 
e começa a reinar a compensação por meio do bem, substituindo a necessidade sinistra de equilibrar por meio do funesto, que gera o mal a partir do mal. O sucesso acontece quando os mais novos aceitam o que receberam dos mais velhos, apesar do preço, e os honram, independentemente do que tenham feito. Os excluídos recuperam seu direito de ser acolhidos e nos abençoam ao invés de nos amedrontarem. Quando lhes damos um lugar em nossa alma, ficamos em paz com eles. A partir do momento que estamos de posse de todos os que nos pertencem, de todos os que fazem parte do nosso sistema familiar, sentimo-nos inteiros e plenos no amor que pode fluir e crescer. Aquilo que se coloca a caminho, sem nenhuma intenção, sem medo e sem vontade de ajudar alguém de qualquer maneira. Por meio do trabalho com os representantes podemos verificar que eles se movimentam sob o impulso da alma e encontram soluções que estão além da influência do constelador ou do terapeuta.

Diante disso, é evidente que, no ato da constelação, cada membro da família que está sendo representado (constelado) precisa visualizar a situação que está sendo posta e, a partir dela, assumir sua parcela de responsabilidade. Somente desse modo é que as ordens aplicadas por esse método serão efetivadas no âmbito familiar.

\section{A CONSTELAÇÃO FAMILIAR E SUA RELAÇÃO COM O DIREITO SISTÊMICO}

Ao pensar na constelação familiar atualmente, é essencial mencionar Samir Storch, Juiz de Direito no Estado da Bahia, que passou a aplicar esse método e tem obtido resultados positivos nas conciliações. Ele é mentor da expressão "Direito Sistêmico", que surgiu com a observação das ordens que regem as relações humanas. Para ele, o direito sistêmico representa a atuação dos operadores do direito em geral não com 
um olhar apenas processualista, mas sim sistêmico, em que as leis sistêmicas são aplicadas ao conflito, seja em vivências coletivas ou em audiências de mediação e conciliação (STORCH, 2016).

No entendimento de Santos (2020), a proposta do direito sistêmico é encontrar a verdadeira solução para o conflito familiar. Para esses casos, uma solução aplicada por uma lei ou por uma sentença judicial pode até trazer algum conforto momentâneo, uma cessação na relação conflituosa, mas, às vezes, não é o método adequado para resolver verdadeiramente a questão e trazer paz às pessoas.

Foi a partir do conhecimento das leis sistêmicas que o Juiz Storch percebeu que poderia aplicar o método de constelação familiar no judiciário. O anseio era que fosse alcançado mais conciliações nas audiências. A primeira vez que usou a técnica foi durante uma disputa pela guarda de uma menina de quatro anos, em 2010. Ele tomou a decisão de utilizar a técnica porque entendeu que, se ele como juiz resolvesse a situação, o drama entre mãe e vó permaneceria. Relata ainda como foi sua primeira experiência com o direito sistêmico: "No dia da audiência, levei comigo um kit de bonecos, que utilizo para a prática da terapia de constelações familiares no atendimento individual - essa terapia também pode ser feita em grupo, com outras pessoas representando membros da família do cliente." (STORCH, 2016).

Em um caso como esse, pode-se identificar facilmente o quanto a colaboração da criança ajudou na resolução da lide, pois a forma como a menina expressa sua escolha deixa claro que a lei por si só não resolveria esse conflito, uma vez que a questão era bem mais profunda. A constelação revelou que a menina amava a mãe e a avó, porém, queria ficar com a mãe. Essas questões o advogado, o juiz e o ministério público não 
conseguem enxergar apenas com a realização da audiência (STORCH, 2016).

É fato que o judiciário está preparado apenas para analisar as questões, como: quem tem mais condições financeiras, se a casa é apropriada para que a criança tenha conforto e um ambiente bom e sadio, quem detém uma vida mais estável. Questões como essas são relevantes e seriam o suficiente se não existisse sentimentos entre mãe e filha, conforme o exemplo citado anteriormente.

\section{A CONSTELAÇÃO FAMILIAR NO DIREITO DE FAMÍLIA E NO JUDICIÁRIO}

As questões de família são, em tese, muito delicadas, uma vez que existem sentimentos envolvidos que somente serão reconhecidos se averiguados profundamente. É necessário que haja uma análise não apenas da pessoa, mas do problema que a envolve, já que possivelmente há um sentimento de desconsideração, de exclusão, rejeição, sentimentos esses que não são visíveis no processo, mas são descobertos por meio da constelação familiar (GONÇALVES, 2017).

Com esse método de constelar, existe a incumbência de encontrar o problema e enfrentá-lo, e é de suma importância trazer as fraquezas e as limitações humanas à tona. Dessa forma, é importante levar o indivíduo a uma reflexão frente a outra parte para que haja o reconhecimento dos sentimentos que gerou a lide, encarar a mágoa, o ódio, reconhecer sua culpa e, assim, encontrar as ordens do amor (STORCH, 2014).

Deve-se entender que a fragilidade humana é exposta pelos sentimentos. A busca por desvendar o que está oculto no conflito ajudaria na maior efetivação dos métodos de autocomposição já existente. É nesse ponto que a constelação familiar é incorporada ao judiciário, uma vez que a maior característica da constela- 
ção é desvendar o que está no profundo de cada pessoa e trazer à tona o sentimento que aprisiona o indivíduo (SANTOS, 2020).

Segundo Santos (2020), a aplicação da constelação familiar tem amparo na lei, pois, com a vigência do código de processo civil, em 18 de março de 2016, foi regulamentada a obrigatoriedade da conciliação e mediação na resolução das lides no judiciário e, nesse processo, as partes e os juízes tiveram de se submeter ao uso da mediação e da conciliação.

Além disso, nota-se que esse entendimento de pacificar por meio da autocomposição é um avanço no judiciário, bem como a ideia de restabelecer o diálogo entre as partes, já que prioriza o restabelecimento dos laços. É possível citar ainda o art. $1^{\circ}$ da Resolução ${ }^{\circ} 125 / 2010$, emitida pelo Conselho Nacional de Justiça (CNJ). In verbis: "Art. $1^{\circ}$ Fica instituída a Política Judiciária Nacional de tratamento dos conflitos de interesses, tendente a assegurar a todos o direito à solução dos conflitos por meios adequados à sua natureza e peculiaridade." (CONSELHO NACIONAL DE JUSTIÇA, 2010).

Em razão do entendimento contido na citada Resolução é que a constelação familiar pode ser usada na área jurídica para alcançar a solução dos conflitos e trazer paz ao sistema familiar para os envolvidos na demanda. O método de constelar no judiciário também é um avanço para a resolução dos conflitos e, por essa razão, alguns Estados estão utilizando essa técnica (SANTOS, 2020).

A aplicação da técnica de constelação no judiciário mostra de forma imparcial e inequívoca o problema, facilitando a compreensão dos envolvidos na demanda. Dessa forma, juízes, servidores e advogados também conseguem entender melhor a lide. Assim, facilita-se a realização de um acordo, atendendo ao interesse dos litigantes, o que resulta paz, equilíbrio e harmonia (GONÇALVES, 2017). 
Os relatos de vivência na constelação familiar são animadores e efetivos. É possível citar um exemplo de processo que envolve divórcio, guarda e pensão alimentícia já deferida e não paga pelo pai. A execução de alimentos já estava em trâmite há quatro anos e ainda não havia sido solucionada pelo judiciário. O pai não pagou a pensão alimentícia, mesmo após ter sido preso por 30 dias (STORCH, 2016).

Todavia, na constelação familiar desse processo, se chegou ao entendimento de que a demanda processual era demais para aquela vara especificamente, refletindo na demora para sentenciar o caso. É fato que o pai não estava disponível para a família, e a mãe sentia-se vítima na separação. Quando cada um assumiu a sua parte da responsabilidade na relação, foi possível acalmar a todos. Após alguns minutos, todos se abraçaram e se acalmaram. Passada uma semana, o cliente entrou em contato com o advogado para dizer que não queria a continuidade do procedimento e passou a pagar a pensão corretamente (ISLIKER, 2016).

Dessa forma, entende-se que o método de constelação familiar não trabalha somente o indivíduo, mas todo o seu sistema. Afinal, as partes que estão envolvidas no processo são chamadas a se colocarem no lugar do outro e, com isso, percebem como o seu agir reflete diretamente no âmbito emocional da outra parte. Assim, as partes verão e sentirão com clareza o caminho para a solução do conflito (SANTOS, 2020).

No entanto, também é de extrema importância compreender os aspectos negativos da constelação familiar. De acordo com Yuki (2019 apud FREITAS, 2019), essa prática precisa ser mais bem desenvolvida e deve ser utilizada com muita cautela no Poder Judiciário. A preocupação é como a técnica pode mexer com as pessoas, já que se trata de uma técnica terapêutica.

Por isso, entende-se que existem alguns limites que devem ser respeitados para aplicar a técnica: 
[...] a técnica não pode ser utilizada para convencimento do magistrado. O juiz que conduz o processo não deveria assistir e nem participar da constelação. A Constelação é um momento das partes envolvidas. É uma ferramenta que vai fazer com que as partes reflitam, por isso tem essa compatibilidade com a conciliação e mediação que pode possibilitar uma reflexão para que a parte possa fazer um acordo, resolvendo por si só (YUKI, 2019 apud FREITAS, 2019).

Além disso, alguns magistrados entendem que o lado negativo da constelação familiar está no fato de que o trabalho poderia ficar comprometido, já que a técnica está muito mais ligada à psicologia do que ao direito propriamente dito (SILVA, 2018).

Outro fator importante para abordar no trabalho está no fato de que a constelação familiar já é utilizada em vários Estados, como Goiás, São Paulo, Rondônia, Bahia, Mato Grosso, Mato Grosso do Sul, Pará, Paraná, Rio Grande do Sul, Alagoas, Amapá e o Distrito Federal. Todos eles utilizam a dinâmica da constelação para ajudar a solucionar os conflitos submetidos ao judiciário.

O método está em conformidade com o Conselho Nacional de Justiça, tanto que é reconhecida a importância da constelação familiar e sua efetividade na resolução dos conflitos familiares a partir de sessões que antecedem a conciliação ou mediação (STORCH, 2014).

Constata-se que, quando uma das partes participa de uma vivência sistêmica antes de uma audiência de mediação, um crescente índice de acordos nos processos é atingido (MENDES; LIMA, 2017).

Como exemplo, tem-se o Tribunal de Justiça de Goiás (TJGO), que foi premiado com o projeto "Mediação Familiar" do $3^{\circ}$ Centro Judiciário de Soluções de Conflitos e Cidadania da Comarca de Goiânia, o que rendeu para o TJGO o primeiro 
lugar no "V Prêmio Conciliar é Legal", promovido pelo CNJ (MENDES; LIMA, 2017).

Com o método de constelação familiar, o TJGO também venceu nas categorias "Maiores Índices de Composição". De acordo com o Núcleo Permanente de Métodos Consensuais e de Solução de Conflitos do tribunal goiano, foram realizados 37,6 mil acordos durante a Semana Nacional da Conciliação, o que resultou na homologação de $\mathrm{R} \$ 190$ milhões em acordo. Do total de audiências realizadas, $86,77 \%$ resultaram em acertos. Somente no último dia dos atendimentos, o valor total arrecadado foi superior a $\mathrm{R} \$ 122$ milhões, com índice de 91,65\% de acordos firmados (ARAÚJO, 2015).

O resultado desse desempenho é em razão do uso da constelação familiar nas audiências de mediação. Segundo o Juiz Paulo César Alves das Neves, coordenador do Núcleo Permanente de Métodos Consensuais de Solução de Conflitos do tribunal e idealizador do projeto, o índice de solução de conflitos com auxílio da técnica é de aproximadamente $94 \%$ das demandas nas ações de pensão alimentícia, divórcio e regulamentação de guarda (SANTOS, 2020).

As sessões de conciliação foram divididas em seis reuniões, com três casos constelados por dia. Em um montante de 90 audiências dos processos nos quais pelo menos uma das partes participou da vivência de constelações, o índice de conciliações foi de $91 \%$. Nos demais casos, foi de $73 \%$. Além disso, nos processos em que ambas as partes participaram da vivência de constelações, o índice de acordos foi de 100\% (BANDEIRA, 2016).

Ademais, nota-se que, além de amortizar o número de ações judiciais, a prática também minimiza a possibilidade de novas divergências nos casos já tratados, assim como permite manter os laços afetivos dessas famílias e reduzir a possibilidade de sofrimento, principalmente de crianças e 
adolescentes. A depender da complexidade do caso, pode ser resolvido na primeira sessão, mas o número de atendimentos vai depender do grau de ressentimento e mágoa dos envolvidos (SANTOS, 2020).

No entendimento de Storch (2016), a constelação familiar é um instrumento que pode melhorar ainda mais os resultados das sessões de conciliação, abrindo espaço para uma justiça mais humana e eficiente na pacificação dos conflitos.

É certo que, por muitos anos, o judiciário sentenciou os processos sem analisar o conflito de forma cultural, já que, em geral, o brasileiro resolve seus problemas com o auxílio da justiça em vez de se valer do diálogo. No entanto, a reincidência processual sempre foi um problema para o judiciário, que tem que lidar com uma quantidade exacerbada de processos pendentes e com a pouca mão de obra oferecida pelos tribunais (BANDEIRA, 2016).

Portanto, a junção da constelação familiar com o Poder Judiciário tende a resolver esses problemas, pois os resultados alcançados são satisfatórios e conseguem englobar o conflito pessoal e o processo judicial. Sem contar que, nos casos já constelados envolvendo ambas as partes, não houve registro de reincidência (STORCH, 2014).

Também é preciso mencionar a contribuição para a reaproximação dos familiares e a reconstrução do elo que foi quebrado. É visível como esse método trabalha a consciência dos envolvidos com intuito de que esses retornem ao sistema familiar de forma harmônica e com paz, voltando a ocupar o lugar que é seu de direito (SANTOS, 2020).

De acordo com Hellinger (2017), pode-se entender que a constelação familiar é mais que uma terapia, é um procedimento de autocomposição, no qual ele acredita que é importante ajudar as pessoas a resolver os conflitos e colocá-las em 
contato com o poder de cura de sua família. No fundo, isso não é apenas terapia, mas sim um trabalho de reconciliação.

No entendimento de Storch, as leis sistêmicas e as constelações familiares, na abordagem desenvolvida por Bert Hellinger, constituem instrumentos poderosos para sensibilizar as partes de um conflito familiar, conduzindo-as a um reconhecimento mútuo, à amenização de mágoas e rancores e a um efetivo respeito entre si, favorecendo a conciliação e evitando o surgimento de futuros litígios (STORCH, 2016).

Para Santos (2020), os conflitos surgem dos relacionamentos, e as relações são orientadas por sentimentos que, na maioria das vezes, são regidos por ordens ocultas. Em razão disso, o uso do método de constelação familiar faz aflorar novas possibilidades de entender o contexto do conflito e assim trazer alívio para as partes envolvidas.

Por fim, compreende-se que a constelação familiar e as leis sistêmicas devem ser observadas como instrumentos poderosos a serem desenvolvidos nas mãos dos operadores do direito para sensibilizar as partes de um conflito familiar, conduzir a um reconhecimento mútuo, diminuir as mágoas e rancores e reconstruir o efetivo respeito entre si, favorecendo a conciliação e evitando o surgimento de futuros litígios (ARAÚJO, 2015).

O estudo das leis sistêmicas pelo judiciário é importante para que os juristas se sensibilizem com as partes envolvidas. Os profissionais envolvidos logo perceberão se algumas das leis sistêmicas foram violadas no seio familiar. Diante dessa observação, pode-se compreender que somente a lei propriamente dita não será o suficiente para resolver a lide em questão (SANTOS, 2020).

É justamente nesse ponto que a constelação surge. A prática de constelar tem efeitos benéficos que englobam desde 
os índices de resolução do conflito até a mudança cultural dos advogados, servidores e juízes. É necessário o entendimento por parte dos operadores do direito no sentido de que o processo não pode ser analisado apenas pela lei, mas deve ser visto como um sistema (SANTOS, 2020).

\section{AS TÉCNICAS UTILIZADAS PARA CONSTELAR}

No que se refere à técnica, é essencial destacar que, para a dinâmica da constelação familiar, é utilizado o auxílio de representantes. A pessoa que vai constelar pede para que o constelado escolha dentro do grupo as pessoas que irão representar sua própria família (STORCH, 2016).

Os representantes são posicionados no espaço da sala pela pessoa que vai fazer a constelação de acordo com a imagem e a situação que ela vê dentro de si. Deve deixar que seu extinto coloque as pessoas em determinada posição, de acordo com a forma que cada um está relacionado com o outro. Nesse momento, começa a constelação familiar, e cada pessoa representante está dentro do campo mórfico daquela família. Ou seja, funciona do seguinte modo: o constelador ouve, faz algumas perguntas-chaves e pede que o constelado escolha os representantes de sua família (SANTOS, 2020).

Hellinger (2017) relata como acontece a constelação familiar. Ele cita um exemplo de um congresso que realizou em Garmisch com doentes. Ele inicia perguntando aos clientes o que lhes aflige. Após essa pergunta, a constelação é iniciada. Um jovem sofre, desde os 18 anos de idade, com uma doença que se manifesta por meio de taquicardia e distúrbios vegetativos. Hellinger diz que precisa de pouquíssimas perguntas para desenvolver esse trabalho. O jovem conta que a irmã gêmea de sua mãe morreu e que ele tem uma irmã mais nova. 
Na sua dinâmica, o terapeuta então prossegue e pede que o jovem posicione as quatro pessoas. Ele pede que sejam escolhidas pessoas do público para representar seu pai, sua mãe, sua irmã e ele mesmo, podendo ser qualquer pessoa, basta que o rapaz as coloque em seus lugares. Hellinger pede que ele vá até cada uma delas, pegue-as com ambas as mãos e encaminhe-as para os seus lugares. Os representantes também não dizem nada nesse momento. Eles devem ser posicionados em relação uns aos outros, tal qual a imagem interior que o jovem tem da sua família naquele exato momento (HELLINGER, 2017).

A constelação familiar é um método onde o cliente assiste a terapia. Ele posiciona os representantes de sua família, responde às perguntas que são pertinentes ao caso e vê os representantes se movimentarem e sentirem as sensações de acordo com o processo terapêutico. Ou seja, assiste à sua vida interpretada por outras pessoas (ARAÚJO, 2015).

Hellinger (2017) confessa que, no momento do processo de constelação, os representantes que são escolhidos para representar a família se sentem como pessoas reais tão logo se inicia a constelação. Por vezes, sentem até os sintomas que os membros dessa família têm, isso sem saber qualquer coisa sobre eles.

De acordo com Hausner (2010), o modo mais efetivo de realizá-la seria em seminários de vários dias, mas entende que atualmente isso não é possível para o judiciário, já que o número de processos em varas de família costuma ser elevado. Cada participante tem a possibilidade de escolher, entre as pessoas do grupo, representantes para si e para membros de sua família. O paciente também constela esses representantes em suas relações recíprocas, de acordo com a imagem interior que ele faz dos membros de sua família.

O fenômeno surpreendente e até agora inexplicável é que os representantes, uma vez posicionados pelo paciente devidamen- 
te centrado, são tomados por um movimento e imediatamente passam a sentir-se como as pessoas reais que representam, manifestando sentimentos delas e por vezes exibindo sintomas físicos semelhantes, quer estejam representando pessoas vivas ou já falecidas. A partir do modo como os representantes se inter-relacionam, dos seus sentimentos, das expressões e dos impulsos que manifestam, o "constelador" e o paciente constelado reconhecem os acontecimentos relevantes da história familiar, as dinâmicas que atuam nessa família e que podem estar em conexão com a doença e os sintomas do paciente (HAUSNER, 2010).

É possível citar alguns exemplos: "uma pessoa que teve um ataque epilético quando representou um epilético, representantes que sentem taquicardia ou sentem o corpo esfriar. Quando questionam as pessoas reais, verificamos que é realmente o que sentem.” (HELLINGER, 2017, p. 13).

O Juiz Storch utiliza o método de constelação familiar nas suas audiências com pessoas e bonecos. Ele discorre como conseguiu resolver uma disputa de guarda com o uso de bonecos:

Quando eu chamei a menina para ser ouvida, coloquei os bonecos em cima da mesa e pedi para que ela posicionasse os brinquedos e montasse a história da família, mostrando que bonecos eram cada membro da família. Perguntamos onde a menina se sentia melhor, o que acontecia quando se aproximava da mãe ou da avó e outros personagens da família. E ela pôde expressar que ela se sentia melhor com a mãe, ainda que apresentasse um carinho grande pela avó e que ficasse bem com as duas (STORCH, 2014).

Além disso, o Juiz Storch, quando faz dinâmica valendo-se de representações, escolhe, entre os presentes, representantes para essa pessoa e para os membros de sua família. O método utilizado no judiciário e na terapia são os mesmos, mudando apenas o conteúdo dos assuntos, mantendo a forma de condu- 
zir. A forma de presidir a dinâmica no judiciário é que difere. Storch relata como ele conduz: inicia com uma palestra sobre os vínculos sistêmicos familiares, as causas das crises nos relacionamentos e a melhor forma de lidar com isso, principalmente de modo a preservar o desenvolvimento sadio dos filhos (STOR$\mathrm{CH}, 2016)$.

Geralmente é perguntado na constelação qual o tipo de processo que a pessoa está envolvida, quer seja divórcio, guarda ou alimentos. No judiciário, são feitas poucas constelações por sessão, em razão da quantidade de processo. Então, são feitas sessões que alcancem o maior número de processos possíveis. Essa constelação no judiciário tem duração média de três horas, e o juiz busca falar de forma didática para que todos entendam (SANTOS, 2020).

Storch (2014) afirma que percebe muita resistência de acordo nas ações de alimentos, guarda e divórcio. Por isso, sempre procura falar frases que não alimentem o conflito. Ele relata que costuma lembrar as partes que foi uma história de amor que os uniu.

Ele relembra ainda que detém cautela para citar as expectativas frustradas, do quanto um percebeu que o outro é diferente, lembra que um percebe o quanto o outro não respeitou a família como foi esperado. A partir dessas frases, as partes dissipam o sentimento de raiva e percebem que, no lugar, se fez uma dor pela falência do relacionamento.

Inclusive, existem frases que são comumente ouvidas pelos filhos de pais separados, tais como: "seu pai não presta"; "ele não paga nem sua pensão"; "ele não vale nada"; "sua mãe não te educa direito, ela não sabe de nada"; "é uma vagabunda"; ou "não quero vocês convivendo com aquele sujeito". É importante relembrar às partes que ambas agora têm filhos juntos e, por isso, uma não pode denegrir a imagem da outra (STORCH, 2016). 
Durante a constelação familiar, essas frases são substituídas. É explicado o quanto é importante deixar os filhos fora do conflito e é sugerido que se diga: "eu e seu pai/sua mãe temos problemas, mas isso não tem nada a ver com você; nós somos adultos e nós resolvemos"; "fique fora disso; você é só nosso filho"; "eu gostei muito do seu pai/sua mãe, e você nasceu de um momento de amor que tivemos"; "eu e seu pai/sua mãe estaremos sempre juntos em você" e "quando eu olho para você, vejo seu pai/sua mãe". Essas explicações têm eficácia, na grande maioria dos casos. Depois disso, as partes reduzem suas resistências e conseguem chegar a um acordo (STORCH, 2016).

Verifica-se ainda que a constelação familiar é realizada antes da audiência de conciliação e mediação. É uma estratégia, pois, depois de resolvido o conflito, as partes já estarão em paz, o sistema familiar já terá sido recomposto e, dessa forma, as chances de elucidação do processo são maiores. As partes são convidadas a participar da constelação; elas não são obrigadas a participarem, não existe uma imposição (ARAÚJO, 2015).

Com o acordo, basta ao juiz homologá-lo para que produza os efeitos de uma sentença. Evita-se, assim, a necessidade de uma instrução processual - com nova audiência para ouvir testemunhas, o que pode ser altamente nocivo no sentido de agravar os rancores e prejudicar a relação - e de uma sentença que imponha uma solução, sujeita a não ser cumprida e deixando insatisfeitos ambos os envolvidos (STORCH, 2016).

O método terapêutico da constelação tem aperfeiçoado a justiça. $\mathrm{O}$ olhar sistêmico no mudo jurídico tem facilitado enxergar os conflitos existentes por trás dos processos. $\mathrm{O}$ resultado disso são os acordos nas audiências de autocomposição e a frequente diminuição de reincidência processual.

A introdução da constelação familiar no mundo jurídico revela que, para conduzir as ações de família, não basta co- 
nhecer o Direito de Família, deve-se saber fazer a ligação de processo com os sentimentos das partes. Entender que as relações humanas são regidas por sentimentos e que, por isso, é preciso restabelecê-los para depois analisar o processo (SANTOS, 2020).

Conforme leciona Hellinger (2017, p.77): "Quando a ordem é restaurada, isso gera um sentimento de alívio, de paz, de possibilidade de fazer algo em conjunto. Esse é o significado da frase simples: "Tudo ficará em ordem".

Em outras palavras, quando os conflitos familiares são constelados e as partes se abrem para solucionar aquela situação verdadeiramente e pôr fim aos sentimentos negativos, é possível restaurar a ordem familiar. Nesse sentido, é primordial que o judiciário e os operadores do direito estejam abertos à introdução desse novo método para que haja uma diminuição no número de processos reincidentes sobre aquele mesmo fato.

\section{CONCLUSÃO}

Diante do exposto, foi possível verificar que a constelação familiar é essencial para resolver de maneira mais aprofundada determinados casos que são submetidos ao poder judiciário. Apesar de se apresentar como um método não convencional, trazendo certo desconforto para aqueles que ainda não conhecem seu funcionamento, nota-se que a constelação familiar tem auxiliado nas conciliações e mediações realizadas nas varas de família.

Em outras palavras, nos Estados em que adotam a constelação, os índices de acordos entre as partes têm aumentado, bem como a restituição dos laços familiares, o que reflete diretamente na diminuição do número de processos reincidentes sobre temas, como execução de alimentos, guarda e divórcio. 
Desse modo, é primordial entender que as técnicas desenvolvidas nessa ferramenta deverão ser aprimoradas e estudadas pelos juristas. Afinal, a tendência é que, a cada dia que passa, a constelação familiar seja mais utilizada no meio jurídico.

Assim, é preciso que os advogados, os juízes, os membros do Ministério Público e as próprias partes sejam instruídos, pois essa nova metodologia exige que haja maior abertura dos profissionais envolvidos, de modo a auxiliar a parte para reconhecer sua parcela de culpa e reestabelecer uma conexão com aquele determinado membro da família cujo conflito havia sido instaurado.

\section{REFERÊNCIAS}

ARAÚJO, E. TJGO é premiado por mediação baseada na técnica de constelação familiar. Agência CNJ de Notícias, 23 jun. 2015. Disponível em: http://cnj.jus.br/noticias/cnj/79702-tjgo-e-premiado-por-mediacao-baseada-na-tecnica-de-constelacao-familiar. Acesso em: 23 mar. 2020.

BANDEIRA, R. Juiz consegue $100 \%$ de acordos usando técnica alemã antes das sessões de conciliação. Agência CNJ de Notícias, 17 nov. 2014. Disponível em: http://www.cnj.jus.br/noticias/cnj/62242-juiz-consegue-100-de-acordos-usando-tecnica-alema-antes-das-sessoes-de-conciliacao. Acesso em: 26 mar. 2020.

CARVALHO, E. V. Constelações familiares sistêmicas. Revista Saúde Quântica, Curitiba, v. 1, n. 1, p. 43-45, jan./dez. 2012 Disponível em: https://www.uninter.com/revistasaude/index.php/saudequantica/article/view/117/49. Acesso em: 19 mar. 2020.

CONSELHO NACIONAL DE JUSTIÇA. Resolução $\mathbf{N}^{0} 125$ de 29/11/2010. Dispõe sobre a Política Judiciária Nacional de tratamento adequado dos conflitos de interesses no âmbito do Poder Judiciário e dá outras providências. Brasília, DF: CNJ, 2010. Disponível em: https://atos.cnj.jus.br/atos/detalhar/atos-normativos?documento $=156$. Acesso em: 2 abr. 2020.

FREITAS, G. do N. P. S. de. Avaliação sobre a técnica da constelação familiar no poder judiciário. 2019. Trabalho de Conclusão de Curso 
(Bacharelado em Direito) - Uniceub, Brasília, 2019. Disponível em: https://repositorio.uniceub.br/jspui/bitstream/prefix/13731/1/21500837. pdf. Acesso em: 28 jul. 2020.

GONÇALVES, C. R. Direito de família. 14. ed. São Paulo: Saraiva, 2017.

HAUSNER, S. Constelações familiares e o caminho da cura: a abordagem da doença sob a perspectiva de uma medicina integral. São Paulo: Cultrix, 2010. Disponível em: https://www.galaxcms.com. br/imgs_redactor/1176/files/Constelac_o_es $\% 20$ Familiares $\% 20 \mathrm{e} \% 20$ o\%20Caminho\%20da\%20Cura.pdf. Acesso em: 19 mar. 2020.

HELLINGER, B. Constelações Familiares: o reconhecimento das ordens do amor. São Paulo: Cultrix, 2017.

ISLIKER, J. O poder da Constelação em 27 relatos. São Paulo: Giostri, 2016.

MENDES, A. T. dos S; LIMA, G. N. O que vem a ser direito sistêmico? In: JUS.COM.BR, jan. 2017. Disponível em: https://jus.com.br/ artigos/54930/o-que-vem-a-ser-direito-sistemico. Acesso em: 27 mar. 2020 .

SANTOS, R. M. dos. A constelação familiar e a efetiva resolução dos conflitos familiares no âmbito da execução de alimentos. In: MONOGRAFIAS BRASIL ESCOLA, [2020]. Disponível em: https://monografias.brasilescola.uol.com.br/direito/a-constelacao-familiar-efetiva-resolucao-dos-conflitos-familiares.htm. Acesso em: 24 mar. 2020.

SCHNEIDER, J. R. A prática das constelações familiares. Patos de Minas: Atman, 2007. E-book. Disponível em: https://constelacoesfamiliarespt.files.wordpress.com/2012/12/a-prc3a1tica-das-constelac3a7c3b5es-familiares-jakob-schneider.pdf. Acesso em: 18 mar. 2020.

SILVA, A. P. S. da. A percepção dos magistrados sobre a utilização da constelação familiar no poder judiciário do distrito federal e territórios. Caderno Virtual, Brasília, DF, v. 1, n. 42, 2018. Disponível em: https:/www.portaldeperiodicos.idp.edu.br/cadernovirtual/article/ view/3299/1514. Acesso em: 30 jul. 2020.

STORCH, S. "Consegui $100 \%$ de conciliações usando uma técnica terapêutica alemã", afirma juiz baiano. Rev. Época, 8 dez. 2014. Disponível em: http://epoca.globo.com/vida/noticia/2014/12/consegui-b- 
100-de-conciliacoesb-usando-uma-tecnica-terapeutica-alema-afirma-juiz-baiano.html. Acesso em: 5 abr. 2020.

STORCH, S. Direito Sistêmico: primeiras experiências com constelações no judiciário. In: DIREITO SISTÊMICO. São Paulo, 23 ago. 2016. Disponível em: https://direitosistemico.wordpress.com/2016/08/23/ publicado-artigo-sobre-as-primeiras-experiencias-com-constelacoes-no-judiciario/. Acesso em: 27 mar. 2020.

Recebido em: 07/04/2020

Aprovado em: 27/07/2020 